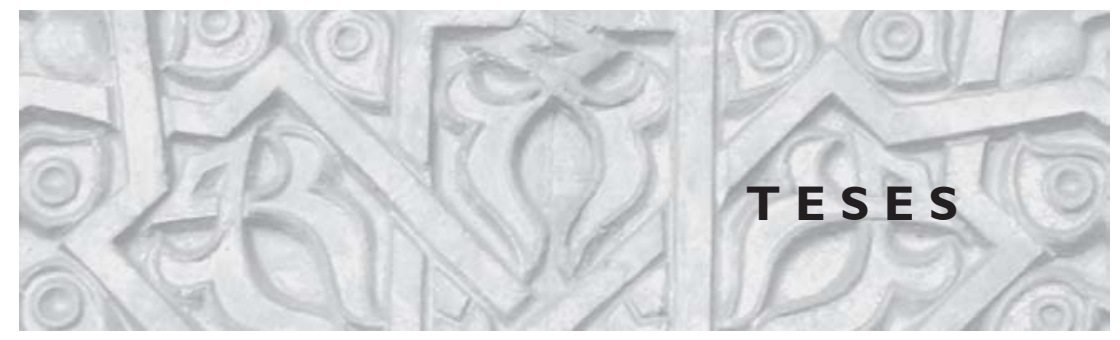

\title{
Programa Saúde da Família: avaliação da atenção à saúde materno-infantil e representações de saúde de mulheres - município de Teixeiras (MG)
}

\author{
Family Health Program: assessment of child-maternal health care and \\ representations of women's health in the municipality of Teixeiras, Minas Gerais
}

\author{
Glauce Dias Costa \\ Dissertação de Mestrado \\ Departamento de Nutrição e Saúde / Universidade Federal de Viçosa \\ Viçosa (MG), 2006
}

A avaliação de programas, serviços e tecnologias na saúde é considerada importante instrumento de apoio às decisões necessárias à dinâmica dos sistemas e serviços de saúde visando à implementação de políticas. Esta dissertação tem como objetivos avaliar a qualidade da atenção à saúde materno-infantil do Programa de Saúde da Família (PSF), em uma perspectiva centrada no cuidado à saúde e na integralidade, bem como analisar as concepções e representações femininas (das mães) do processo saúde-doença do município de Teixeiras, em Minas Gerais. Realizou-se um estudo de corte transversal, com abordagem quantitativa e qualitativa, tendo participado da pesquisa 161 mães de crianças menores de dois anos, 33 gestantes e 35 profissionais de saúde atuantes no PSF do município. Na avaliação da atenção à saúde da criança e da gestante pelo Programa, de acordo com as proposições de Donabedian (1990), utilizou-se um sistema de escores específicos para análise de estrutura, processo e resultado e seus respectivos atributos, estabelecendo-se os cenários incipiente (0\%-33,3\%), intermediário (33,4\%-66,6\%) e avançado (66,7\%-100\%). Com relação às representações de saúde utilizou-se a técnica de análise de conteúdo (Minayo, 1992), construindo atrativos semânticos e indicadores de saúde na busca de expressar a representação do processo saúde-doença pelas mães. Utilizaram-se questionários semiestruturados na coleta das informações, aplicados por um único entrevistador devidamente treinado. Os resultados indicaram que o PSF, na atenção a saúde das crianças e gestantes, apresenta cenário intermediário, caracterizado por uma atenção fragmentada, mas com alguns avanços na organização da atenção para esses grupos. Na atenção a saúde das crianças foram consideradas incipientes: instalações físicas; qualidade do cuidado nas ações direcionadas ao controle da diarréia e às infecções respiratórias; participação comunitária; a intersetorialidade. Os avanços estiveram relacionados ao acolhimento realizado pelo PSF e à resolubilidade. $\mathrm{Na}$ atenção a saúde das gestantes os atributos caracterizados como incipientes foram instalações físicas, atividades educativas, intersetorialidade e participação comunitária; os atributos caracterizados como intermediários foram recursos materiais, avaliação clínica, cartão da gestante, referência e contra-referência e resolubilidade; e os atributos avançados foram acolhimento e acessibilidade. As mães expressaram uma visão de saúde-doença pluralista, das mais holísticas às mais biomédicas; das mais relacionais às mais individuais. Um dado interessante encontrado no estudo foi a apresentação da busca da felicidade como um conceito de saúde pelas mães, retomando aspectos filosóficos aristotélicos e espinosistas. Não obstante, a representação da saúde como ausência da doença aparece também como ponto importante no relato das mães. Uma vez que os construtos são sociais (e não individuais) e recebem grande influência da cultura local e macrossocial, o modelo assistencial hegemônico vigente fornece ainda fortes referenciais para interpretar tais experiências. A superação do modelo biomédico, ainda dominante nas práticas de saúde locais somente se concretizará com a participação de todos os atores sociais envolvidos. Essa participação poderá viabilizar-se desde que gestores e profissionais de saúde compreendam o papel ativo dos usuários e de suas representações no planejamento, na formulação e na avaliação das ações e atividades desenvolvidas pelo programa, fomentando a saúde em uma base ética e política. 